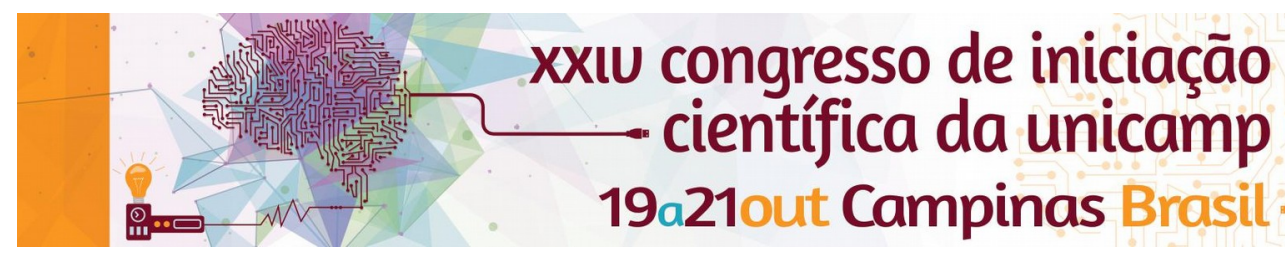

\title{
Reconstrução de Fragmentos de um Sinal de Áudio usando o Modelo Linear Preditivo.
}

\section{Mateus Sangalli*, Marcos Eduardo R.V. Mesquita}

\section{Resumo}

Processamento de sinais é uma área do conhecimento com muitas aplicações, incluindo, entre outras, o processamento de áudio e vídeo, telecomunicação, sistemas de radar e medicina. Nesse trabalho de iniciação científica, estudamos o problema de reconstrução de um fragmento de um sinal de áudio discreto no tempo. A principal ferramenta utilizada para a reconstrução do fragmento foi o modelo linear preditivo, combinado com o método dos quadrados mínimos e técnicas de otimização não-linear. Para avaliar a eficiência dos métodos desenvolvidos, efetuamos alguns experimentos computacionais utilizando dados sintéticos e reais.

\section{Palavras-chave:}

Processamento de sinais, modelo linear preditivo, métodos de otimização

\section{Introdução}

Processamento de sinais é uma área que se desenvolveu rapidamente nas últimas décadas, principalmente devido ao avanço dos computadores digitais ${ }^{1}$. Aplicações dessa área, incluem, entre muitas outras, processamento de áudio, processamento de vídeo, telecomunicação, sistemas de radar e medicina ${ }^{2}$. Nesse projeto de iniciação científica, estudamos o problema de reconstrução de um fragmento perdido de um sinal ${ }^{2}$. Esse problema surge, por exemplo, na restauração de áudios corrompidos, falha no sistema de captura do sinal ou devido à perda em canais de telecomunicação. A Figura 1 ilustra um sinal no qual um fragmento foi perdido.

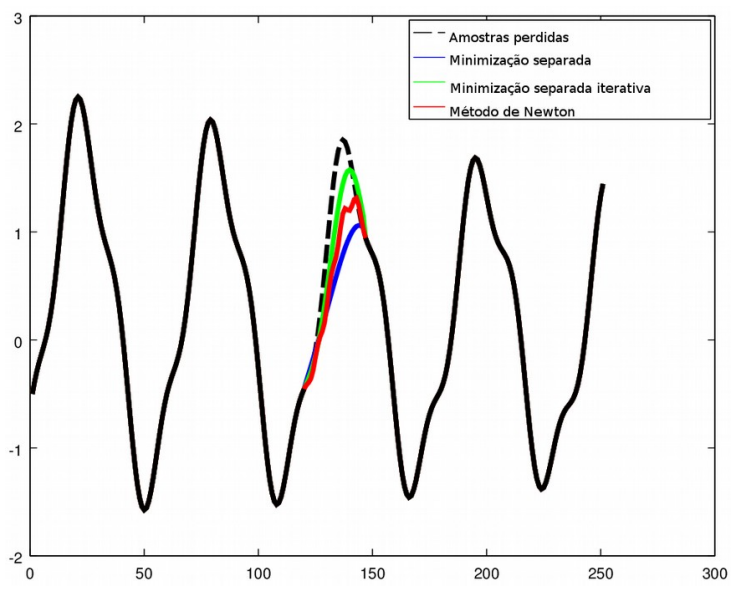

Figura 1. Gráfico de um sinal com um fragmento perdido e as estimativas obtidas utilizando três abordagens.

\section{Resultados e Discussão}

No modelo linear preditivo, a amostra $x(t)$ de um sinal discreto no tempo é dada pela combinação linear das $p$ amostras anteriores somada um erro $e(t)$, ou seja,

$$
x(t)=\sum_{k=1}^{p} h_{k} x(t-k)+e(t),
$$

em que $h_{1}, h_{2}, \ldots, h_{p}$ são parâmetros do modelo. Tanto os parâmetros $h_{1}, \ldots, h_{p}$ como as amostras perdidas foram estimados minimizando o erro quadrático

$$
E=\sum_{t \in T}\left[x(t)-\sum_{k=1}^{p} h_{k} x(t-k)\right]^{2},
$$

utilizando diferentes abordagens:

1. Minimização Separada. Primeiro determina-se os parâmetros $h_{1}, \ldots, h_{p}$ utilizando somente as amostras conhecidas. Depois o fragmento perdito é estimado usando (1). Ambos estágios são formulados como um problema de quadrados mínimos linear ${ }^{2}$.

2. Minimização Separada Iterativa. Conhecendo uma estimativa para fragmento perdido, calcula-se novamente os parâmetros $h_{1}, \ldots, h_{p}$. Posteriormente, (1) é utilizado novamente para obter melhores estimativas do fragmento perdido. Repete-se o processo até não haver mudanças significativas nas estimativas.

3. Método de Newton. Utilizamos o método de Newton para minimizar (2) como função de ambas amostras perdidas e dos parâmetros $h_{1}, \ldots, h_{p}$.

Implementamos no software GNU Octave as três abordagens e realizamos experimentos computacionais com sinais sintéticos e reais. A Figura 1 ilustra o resultado obtido pelas três abordagens.

\section{Conclusão}

Nesse projeto vimos como um fragmento perdido de um sinal discreto no tempo pode ser reconstruído minimizando o erro quadrático do modelo linear preditivo. De um modo geral, a minimização separada proposta por Vaseghi tem baixo custo computacional mas apresentou os piores resultados. Em contraste, o método de Newton apresentou resultados melhores, mas também apresentou um elevado custo computacional.

\section{Agradecimentos}

Agradecemos ao Programa Institucional de Bolsas de Iniciação Cientifica (PIBIC) e ao Serviço de Apoio ao Estudante (SAE) da Unicamp.

${ }^{1}$ Proakis, J.G. e Manolakis, D.G. Digital Signal Processing. Pearson Prentice Hall, Upper Saddle River, New Jersey - USA. 4th edition, 2007.

${ }^{2}$ Vaseghi, S. Advanced Digital Signal Processing and Noise Reduction. John Wiley and Sons, Chichester, West Sussex - UK. 4th edition. 2009. 